\title{
Biomechanical assessment of composite versus metallic intramedullary nailing system in femoral shaft fractures: A finite element study
}

\author{
Saeid Samiezadeh ${ }^{\text {a }}$, Pouria Tavakkoli Avval ${ }^{\text {a }}$, Zouheir Fawaz ${ }^{\text {, }}$, Habiba Bougherara a,* \\ a Department of Mechanical and Industrial Engineering, Ryerson University, Toronto, ON, Canada \\ ${ }^{\mathrm{b}}$ Department of Aerospace Engineering, Ryerson University, Toronto, ON, Canada
}

\section{A R T I C L E I N F O}

\section{Article history:}

Received 16 January 2014

Accepted 7 May 2014

\section{Keywords:}

Intramedullary nail

Femoral fracture

Stress shielding

Finite element method

Hybrid composite

\begin{abstract}
A B S T R A C T
Background: Intramedullary nails are the primary choice for treating long bone fractures. However, complications following nail surgery including non-union, delayed union, and fracture of the bone or the implant still exist. Reducing nail stiffness while still maintaining sufficient stability seems to be the ideal solution to overcome the abovementioned complications.

Methods: In this study, a new hybrid concept for nails made of carbon fibers/flax/epoxy was developed in order to reduce stress shielding. The mechanical performance of this new implant in terms of fracture stability and load sharing was assessed using a comprehensive non-linear FE model. This model considers several mechanical factors in nine fracture configurations at immediately post-operative, and in the healed bone stages.

Results: Post-operative results showed that the hybrid composite nail increases the average normal force at the fracture site by $319.23 \mathrm{~N}(P<0.05)$, and the mean stress in the vicinity of fracture by $2.11 \mathrm{MPa}(P<0.05)$ at $45 \%$ gait cycle, while only $0.33 \mathrm{~mm}$ and $0.39 \mathrm{~mm}(P<0.05)$ increases in the fracture opening and the fragments' shear movement were observed. The healed bone results revealed that implantation of the titanium nail caused $20.2 \%$ reduction in bone stiffness, while the composite nail lowered the stiffness by $11.8 \%$ as compared to an intact femur.

Interpretation: Our results suggest that the composite nail can provide a preferred mechanical environment for healing, particularly in transverse shaft fractures. This may help bioengineers better understand the biomechanics of fracture healing, and aid in the design of effective implants.
\end{abstract}

(C) 2014 The Authors. Published by Elsevier Ltd. This is an open access article under the CC BY-NC-SA license (http://creativecommons.org/licenses/by-nc-sa/3.0/)

\section{Introduction}

Intramedullary (IM) nails are used as internal fracture fixation tools to treat diaphyseal fractures in long bones. They are implanted within the IM canal and fixed by interlocked screws to stabilize the bone fragments during the healing process. Despite all the advancements in IM nail design used for treating femoral diaphyseal fractures, complications remain such as failure of the nail or screws, delayed union, non-union, and bone refracture (Braten et al., 1995). In virtually all femoral shaft fractures, the definitive treatment protocol is to implant an anterograde, reamed, locked IM nail (Browner, 2009). Such placement of nails can facilitate transfer of the load and stress through both the fractured femur and/or the nail itself. Titanium (Ti) alloys commonly used in manufacturing IM nails, provide appropriate stability at fracture site. However, their high rigidity causes the nail to bear the majority of the load once implanted, shielding the bone from the stress it would

\footnotetext{
* Corresponding author at: Department of Mechanical and Industrial Engineering, Ryerson University, 350 Victoria Street, Toronto, ON M5B 2K3, Canada

E-mail address: habiba.bougherara@ryerson.ca (H. Bougherara).
}

naturally experience (Cheung et al., 2004). The reduction of the mechanical stress on the femur results in bone resorption at the vicinity of the implant over time which is referred to as stress shielding (Wolff et al., 1986). This condition makes the bone prone to refracture.

It was shown in in-vivo studies that reducing the stiffness of the implants accelerates the healing process and enhances the quality of the callus (Sha et al., 2009; Utvag and Reikeras, 1998). However, implants that are too flexible have shown poor fixation and subsequent complications, such as malunion or non-union (Epari et al., 2007; Kenwright and Goodship, 1989; Terjesen and Apalset, 1988). Conflicting results in studies that have investigated the effect of fixation rigidity on fracture healing leave the question of optimum fixation rigidity unsolved (Browner, 2009; Epari et al., 2007). Ideally, the fixation implant should counter bending, torsion, and shear stress adequately, while countering compressive stress fractionally (Poitout, 2004).

The current IM nails made of Ti absorb between 70 and $74 \%$ of total axial force during the stance phase and $91 \%$ during the swing phase of gait (Cheung et al., 2004), shielding the fracture from compressive loads and resulting in bone resorption in post-healing stages. In an isotropic material which is the choice in IM nails, axial, bending, and torsional stiffnesses could not be altered without directly affecting one 
another. Fiber reinforced composites have been recently used in biomedical implants because of their high strength, low rigidity, and corrosion and fatigue resistance (Mantripragada et al., 2013). Most importantly, they have the possibility to be tailored and adapted based on specific requirements through changing the arrangement or volume fraction of the fibers (Cifuentes et al., 2012). The use of a hybrid composite material provides even greater customizability, particularly in altering the stiffness in different directions to facilitate an optimal mechanical environment for fracture healing (Bagheri et al., 2013).

Any effort to improve fracture healing and to reduce stress shielding in current IM nailing techniques requires a good understanding of the biomechanics of fracture fixation and fracture healing in long bones. Many mechanical factors are involved in fracture healing. The most dominant ones are the rigidity of the fixation device, the fracture configuration, the amount of stress occurring at both ends of fracture, and the relative motion of the fragments (Aro and Chao, 1993; Augat et al., 2003; Eveleigh, 1995). While several researchers have investigated the biomechanics of IM nailing in long bones through simulations and biomechanical testing, few have considered the main factors involved in fracture healing. Most of the models proposed in recent literature to simulate IM nailing (Bougherara et al., 2009; Cheung et al., 2004) did not consider the presence of fractures and also ignored the interaction between the IM nail and the inner wall of medullary canal. Those models that did include fractures (Montanini and Filardi, 2010; Shih et al., 2012) failed to consider non-transverse fractures, or fractures occurring at varying locations along the length of the bone shaft, which are quite common.

The purpose of this study, therefore, was to develop a hybrid composite (carbon fiber (CF)/flax/epoxy) material for IM nails and to assess its mechanical performance by using a comprehensive finite element model capable of capturing dominant mechanical factors involved in fracture healing. The proposed hybrid composite takes advantage of carbon fibers with an established research history in fracture fixation devices and with confirmed biocompatibility properties (Bagheri et al., 2013). They would provide superior strength and stiffness at outer layers where they were used. Flax fibers were also used to obtain the required axial, bending and torsional stiffnesses. Moreover, the radiolucency (i.e. having greater transparency to X-ray photons) (Suchý et al., 2011) of the proposed hybrid composite makes it compatible with modern medical imaging, such as computed tomography (CT) or magnetic resonance imaging (MRI).

It was hypothesized that the proposed hybrid composite would result in a more desirable condition for healing, as it would provide sufficient stability and reproduce the strain distribution of an intact femur in the healed stage through increasing of the load transferred to the bone. This would subsequently encourage bone regrowth and prevent bone degradation.

\section{Finite element analysis}

\subsection{Computer-aided design (CAD) model}

A three dimensional (3D) model of a large left fourth-generation composite femur (model 3406, sawbones, Vashon, WA, USA) was employed, which was developed and validated in previous studies (Tavakkoli Avval et al., 2014; Zdero et al., 2010). The new generation of synthetic bone has been shown to have no significant differences in its elastic or failure properties when compared to an intact bone (Heiner, 2008).

The geometry of a $420 \mathrm{~mm}$ Stryker T2 femoral nail (Stryker, Mahwah, NJ, USA) was obtained by reverse engineering. The nail was modeled as a shell to ensure it would be capable of being used as a composite laminate later in simulations.

Assemblage of the nail and bone was completed in SolidWorks (Dassualt Systèmes, Concord, MA, USA) based on the manufacturerprovided instructions. Four $5 \mathrm{~mm}$ locking screws were modeled as solid bodies and positioned to protrude approximately $2 \mathrm{~mm}$ out of the femur (Cheung et al., 2004). The intersecting volumes of the bone-nail and bone-screws in the proximal and distal ends were then subtracted from the model.

\subsection{Gait loads and boundary conditions}

The present study employed a comprehensive load case at $45 \%$ gait cycle presented by Duda et al. $(1997,1998)$ and simplified by Bitsakos et al. (2005). It included contributions from five major muscles (i.e. m. gluteus maximus, m. gluteus medius, m. gluteus minimus, m. psaos, and $\mathrm{m}$. abductor magnus) and the hip joint force. This reduced muscle system was selected because previous studies (Bitsakos et al., 2005; Duda et al., 1998) have shown that the aforementioned muscles have the most significant effect on the internal loads of the femur at $45 \%$ of the gait cycle due to their magnitudes and directions. The $\mathrm{m}$. abductor magnus and $\mathrm{m}$. abductor mimimus were not considered in this study as they have negligible effects at this instant of the gait cycle. The muscle attachment points obtained by Duda et al. (1998) and scaled for use on the 3rd generation composite femur by Cheung et al. (2004) were employed, as there is no geometrical difference between the 3rd generation and 4th generation composite femurs.

\subsection{Meshing and material properties}

The assembled CAD model was imported into ANSYS Workbench (ANSYS Inc., Canonsburg, PA, USA) to generate a FE model. Synthetic bone was assumed to be isotropic with linear elastic properties (Table 1 ) as reported by the manufacturer and employed in previous studies (Gardner et al., 2010; Grassi et al., 2013; Heiner, 2008). Tetrahedral 10-noded elements, with three degrees of freedom at each node, were utilized to mesh solid bodies (Papini et al., 2007; Viceconti et al., 1998). The IM nail was meshed with 4-noded elements having six degrees of freedom at each node. This type of element has the capability of modeling thin to moderately-thick shell structures as well as composite shells or sandwich structures. The metallic IM nail was made of a Ti-6AL-4V and was assigned a $3.2 \mathrm{~mm}$ thickness. This model involved a sandwich structure made of a 12-layer flax/epoxy core spanned by $2 \mathrm{CF} /$ epoxy thin layers at the inner and outer surfaces (16 layers in total), with a unidirectional fiber orientation parallel to the nail axis. Each laminae were assumed to have a thickness of $0.2 \mathrm{~mm}$. This configuration has been recently shown to be a promising candidate for use in fracture fixation implants in long bones by providing efficient load sharing, and proper stability (Bagheri et al., 2013; Charlet et al., 2010). The convergence of mesh refinement was checked with the "relevance" option in ANSYS Workbench with a value of -100 indicating a very coarse mesh and 100 corresponding to an extremely fine mesh. A set of simulations showed that a value of 75 will result in convergence, and thus further increasing the relevance will not change the strain values by more than $1 \%$.

\subsection{Configurations used and contact modeling}

In order to thoroughly investigate the biomechanics and performance of nailing in femoral shaft fractures, two main stages were considered: immediately post-operative (PO) and completely healed bone (HB).

In the PO stage, three fracture locations with three fracture angles in each ( 9 configurations in total) were investigated as depicted in Fig. 1. For the angled fractures, proximal medial to distal lateral (PMDL) and proximal lateral to distal medial (PLDM) fractures were considered. The screw threads were not modeled and the contact between the bone and the screws was assumed to be bonded (Cheung et al., 2004). The bone and the nail were assumed to have nonlinear frictionless contact in which an initial gap would be allowed and the surfaces might come into contact during the simulation (Montanini and Filardi, 
Table 1

Linear elastic isotropic (Ti-6AL-4V, cortical, and trabecular bone) and transversely isotropic (flax/epoxy and carbon/epoxy) material properties used in the current study.

\begin{tabular}{|c|c|c|c|c|c|c|c|c|c|c|c|}
\hline \multicolumn{6}{|l|}{ Composite } & \multirow{2}{*}{\multicolumn{2}{|c|}{ Ti-6AL-4V }} & \multicolumn{4}{|l|}{ Bone } \\
\hline \multicolumn{3}{|l|}{ Flax/epoxy ${ }^{a}$} & \multicolumn{3}{|c|}{ Carbon/epoxy ${ }^{\mathrm{a}}$} & & & \multicolumn{2}{|c|}{ Cortical } & \multicolumn{2}{|c|}{ Trabecular } \\
\hline $\begin{array}{l}\mathrm{E} \\
(\mathrm{GPa})\end{array}$ & $\begin{array}{l}\mathrm{G} \\
(\mathrm{GPa})\end{array}$ & $v$ & $\begin{array}{l}\mathrm{E} \\
(\mathrm{GPa})\end{array}$ & $\begin{array}{l}\mathrm{G} \\
(\mathrm{GPa})\end{array}$ & $v$ & $\begin{array}{l}\mathrm{E} \\
(\mathrm{GPa})\end{array}$ & $v$ & $\begin{array}{l}\mathrm{E} \\
(\mathrm{GPa})\end{array}$ & $v$ & $\begin{array}{l}\mathrm{E} \\
(\mathrm{GPa})\end{array}$ & $v$ \\
\hline$E_{x}=35$ & $\mathrm{G}_{\mathrm{xy}}=5$ & $v_{\mathrm{xy}}=0.3$ & $\mathrm{E}_{\mathrm{x}}=121$ & $G_{x y}=4.7$ & $v_{\mathrm{xy}}=0.27$ & 113.8 & 0.342 & 16.7 & 0.26 & 0.155 & 0.3 \\
\hline $\mathrm{E}_{\mathrm{y}}=2$ & $\mathrm{G}_{\mathrm{xz}}=5$ & $v_{\mathrm{xz}}=0.3$ & $\mathrm{E}_{\mathrm{y}}=8.6$ & $G_{x y}=4.7$ & $v_{\mathrm{xz}}=0.27$ & - & - & - & - & - & - \\
\hline $\mathrm{E}_{\mathrm{z}}=2$ & - & $v_{\mathrm{yz}}=0.4$ & $E_{z}=8.6$ & - & $v_{\mathrm{yz}}=0.4$ & - & - & - & - & - & - \\
\hline
\end{tabular}

a The layers were made of unidirectional (UD) prepreg flax and carbon sheets, with X-axis considered as reference axis for fiber orientation.

2010). The same type of contact was assumed for the fracture surfaces to account for sliding, separation, and force transmission between fracture fragments.

In the HB stage, the same assumptions were made except for those regarding the fracture contact, as bone continuity was assumed to be recovered at this stage.

\subsection{Output parameters}

A total of seven parameters were employed to capture the mechanical factors involved in fracture healing based on the literature (Antekeier et al., 2005; Aro and Chao, 1993; Augat et al., 2003; Browner, 2009; Bucholz et al., 1987; Shih et al., 2012). They included compressive normal force and contact bending moment at the fracture site, fracture opening and shear movement, bone mean stress around the fracture, maximum deformation of the structure, and maximum

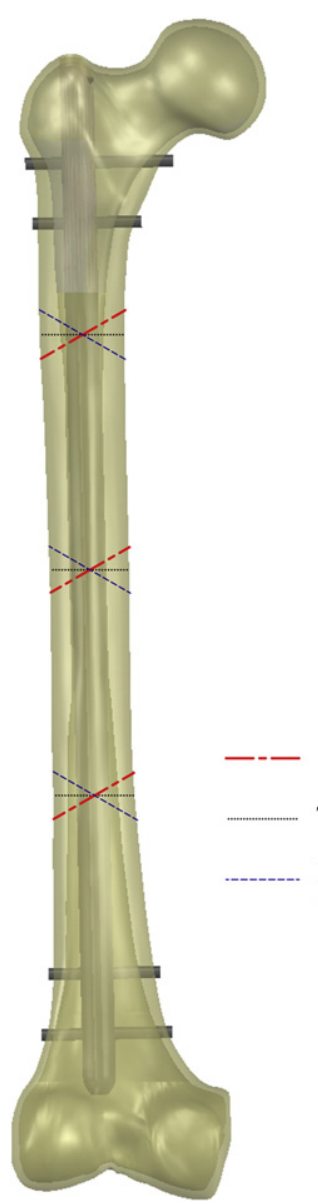

Proximal medial to distal lateral (PMDL) fracture

Transverse fracture

Proximal lateral to distal medial (PLDM) fracture

Fig. 1. Immediate post-operative (PO) model of the fractured femur. Three locations were chosen to account for proximal third, middle third, and distal third femoral shaft fractures. Three values $\left(-30^{\circ}, 0\right.$, and $\left.30^{\circ}\right)$ were considered for the fracture angle, with 0 as transverse, $-30^{\circ}$ indicating a PLDM, and $30^{\circ}$ as PMDL angled fracture. stress in the nail. A description of each parameter is provided in Appendix A.

\subsection{Statistical analysis}

Consideration of all possible combinations of the fracture angles and locations led to a total of 9 data sets, which cover almost all transverse femoral shaft fractures. Using SPSS Statistics 22 (SPSS Inc., Chicago, IL, USA) the significance of the changes in the parameters (with the use of new material) was analyzed using a paired-samples T-test, with a $P$ value less than 0.05 deemed as significant.

\section{Results}

\subsection{PO stage}

Fig. 2 shows stress distribution in a typical fracture configuration that was fixed with Ti and composite IM nails. Compressive normal forces and contact bending moments increased $(P=0.003)$ by 319.23 $\mathrm{N}$ and $5.36 \mathrm{~N} \cdot \mathrm{m}$ respectively when the composite IM nail is used instead of the Ti IM nail (Fig. 3a-b). The use of the composite IM nail resulted in an increase of $2.11 \mathrm{MPa}(P=0.0005)$ in the mean value of the vonMises stress in the bone at the vicinity of the fracture (Fig. $3 \mathrm{c}$ ), and also an increase of $331.12 \mathrm{MPa}(P=0.0005)$ in the maximum stress in the implant (Fig. 4a) as opposed to the Ti nail. The location of the maximum stress remained constant, except in the mid-shaft transverse, mid-shaft PMDL, and distal PMDL angled fractures. The fracture opening and the shear movement between fracture surfaces, as illustrated in

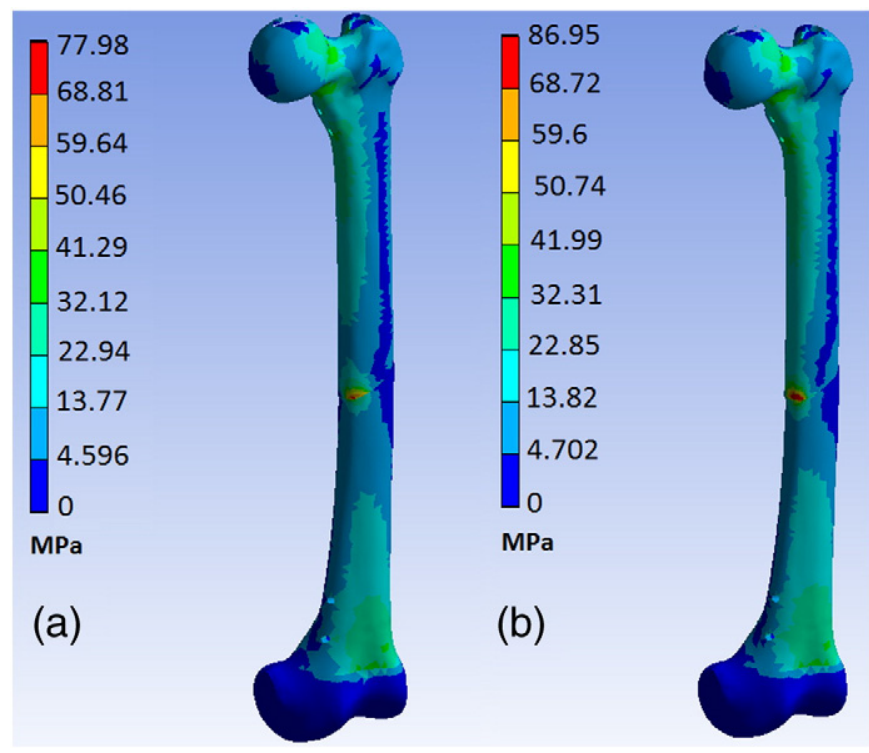

Fig. 2. A typical graph of the von-Mises stress in the bone after the implantation of a) $\mathrm{Ti}$ and b) CF/flax/epoxy IM nail. Note the higher stress levels in the bone implanted with the composite IM nail. 

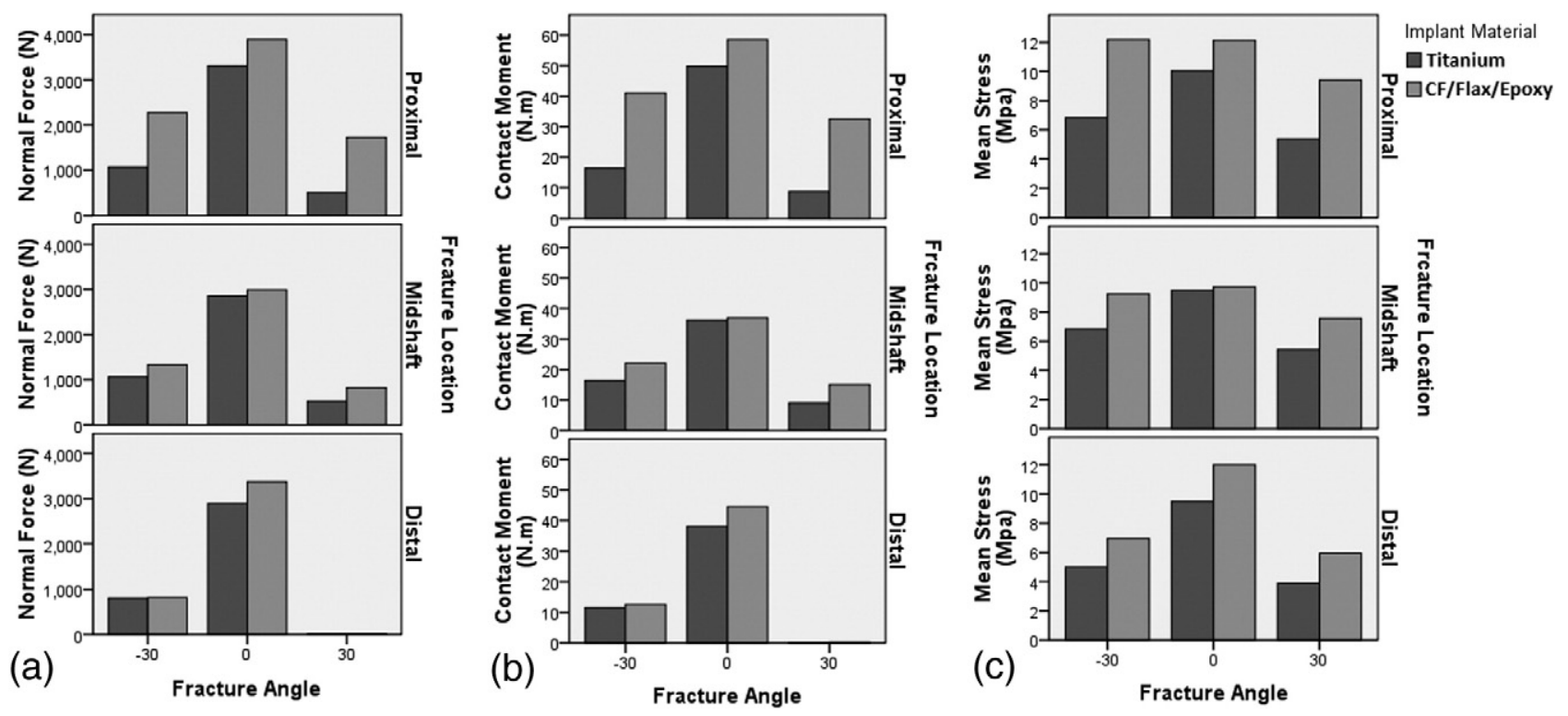

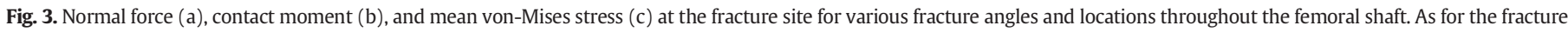
angle, 0 represents a transverse, $-30^{\circ}$ represents a PLDM, and $30^{\circ}$ represents a PMDL angled fracture.

Fig. $4 \mathrm{~b}-\mathrm{c}$, were found to increase $(P=0.004)$ by an average of $0.33 \mathrm{~mm}$ and $0.39 \mathrm{~mm}$ respectively. The maximum penetration in nonlinear contact among all configurations was found to be $0.029 \mathrm{~mm}$. Fig. 5 shows the von-Mises stress contours in the Ti nail and locking screws at different fracture locations and angles. No failure of the composite IM nail was observed in any configuration according to Tsai-Hill failure criteria.

\subsection{HB stage}

It was found that the Ti IM nail reduced the average von-Mises stress in the bone by $22 \%$ when compared to the intact bone, while a $15.4 \%$ reduction was observed with the use of the composite IM nail (Fig. 6). Considering the maximum deformation of the structure in Fig. 6, the implantation of the Ti IM nail caused a $20.2 \%$ reduction in the deformation, while the composite IM nail lowered the deformation by $11.8 \%$.

\subsection{Verification of FE results with the previous studies}

For the finite element results to be reliable, it is essential that they are verified against experimental data for at least one load case (Viceconti et al., 2005). The HB results were compared to similar studies in the literature (Bougherara et al., 2009; Papini et al., 2007). Strain values at five different locations were obtained for Ti nail and compared to the measurements performed by Bougherara et al. (2009) (Fig. 7). To mimic their experimental test setup, an axial load of $580 \mathrm{~N}$ was applied on the femoral head and the bone was assigned the material properties of a 3rd generation composite femur. A good correlation $\left(R^{2}=0.926\right)$ was found between the strain values obtained from the current FE model and those that were experimentally measured (Table 2 ). The obtained stiffness $(1378.8 \mathrm{~N} / \mathrm{mm}$ ) also compared favorably with that reported by the prior investigation for retrograde IM nail implantation in synthetic
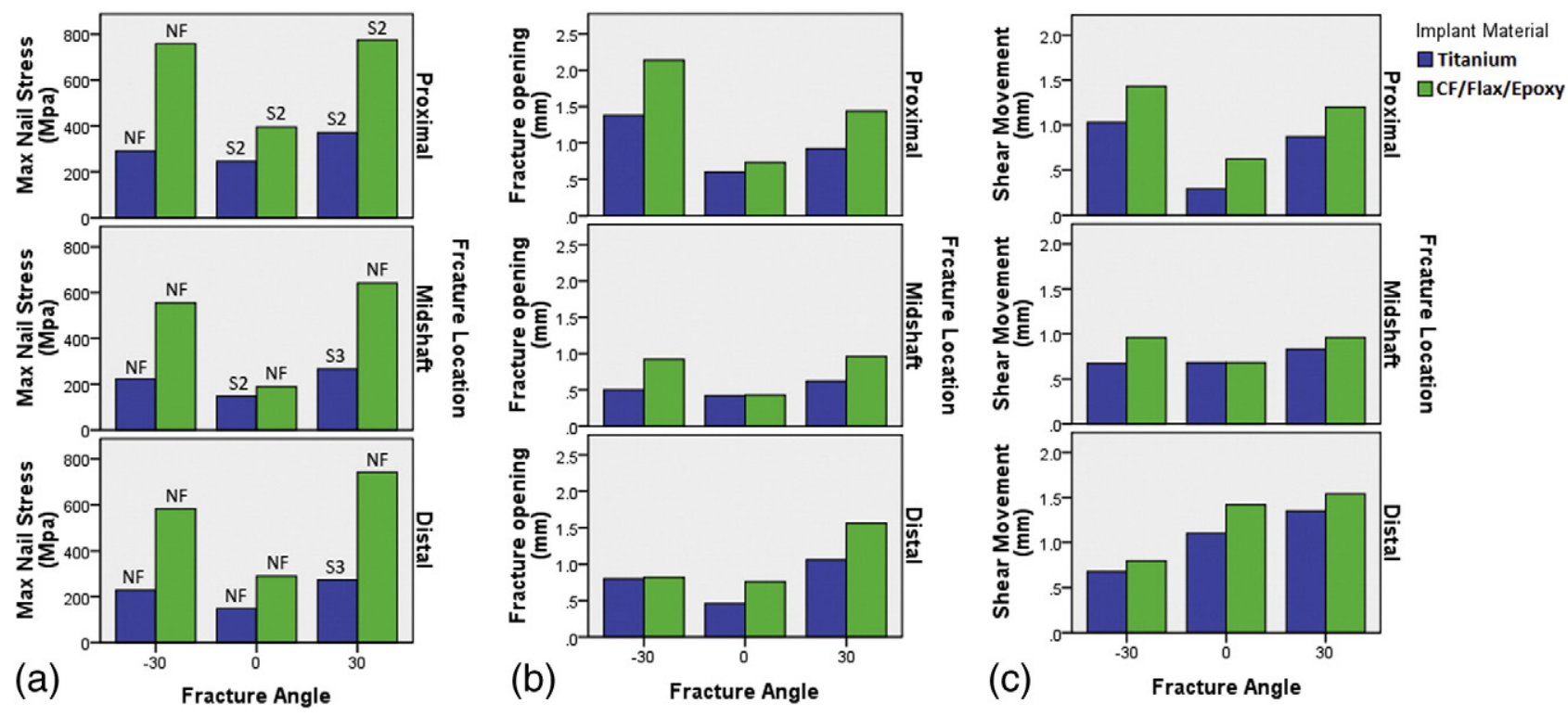

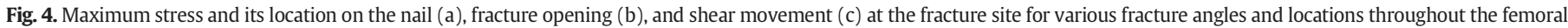

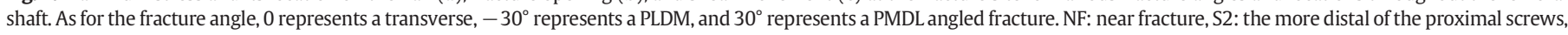
S3: the more proximal of the distal screws. 

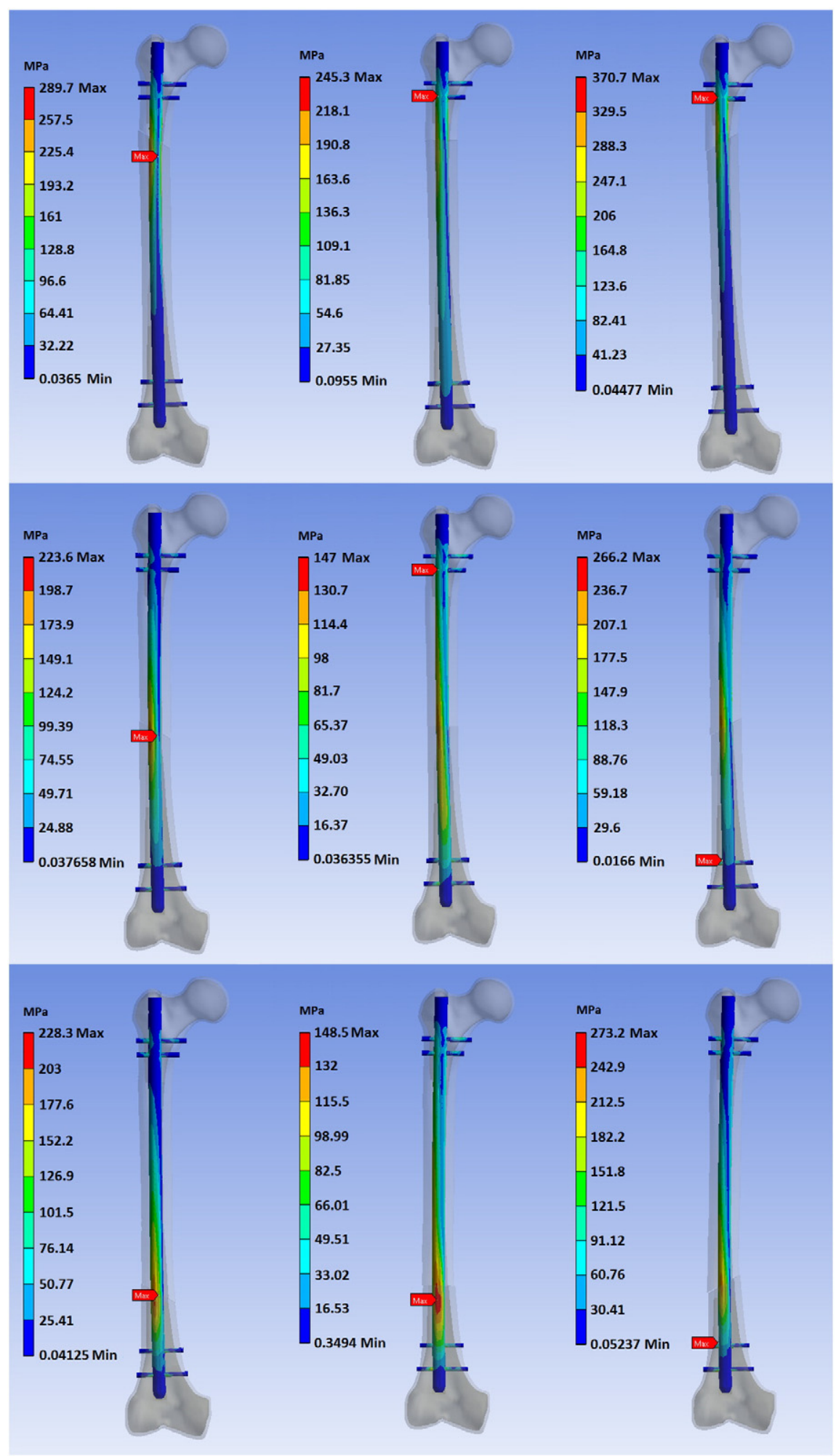

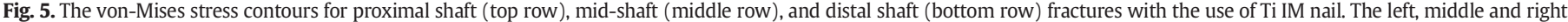
columns depict PLDM angled, transverse, and PMDL angled fractures.

femurs (1168.8 N/mm) (Bougherara et al., 2009), and with that reported for intact synthetic femurs (1290 $\pm 30 \mathrm{~N} / \mathrm{mm}$ ) (Papini et al., 2007).

\section{Discussion}

The primary goal of fracture treatment is to provide an optimum mechano-biological environment for each stage of fracture healing
(Browner, 2009). Compressive normal stress at the fracture site has shown to boost fracture healing by stimulating remodeling of the callus, while excessive shear movements result in delayed union or poor callus quality (Augat et al., 2003; Poitout, 2004). Reducing the stiffness of the fixation device could favorably increase the load levels at the fracture site, but it may also compromise the stability of the fracture by increasing the unfavorable (e.g. shear and torsional) interfragmentary 


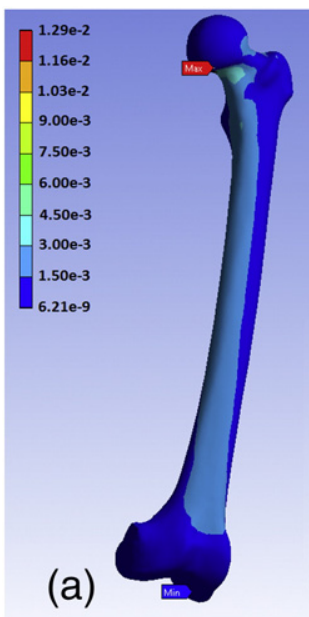

(b)

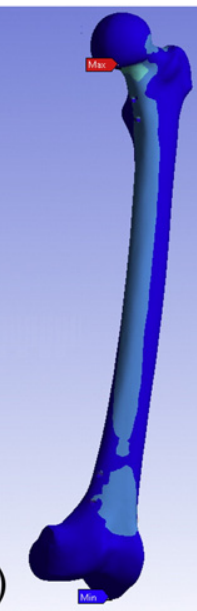

(c)
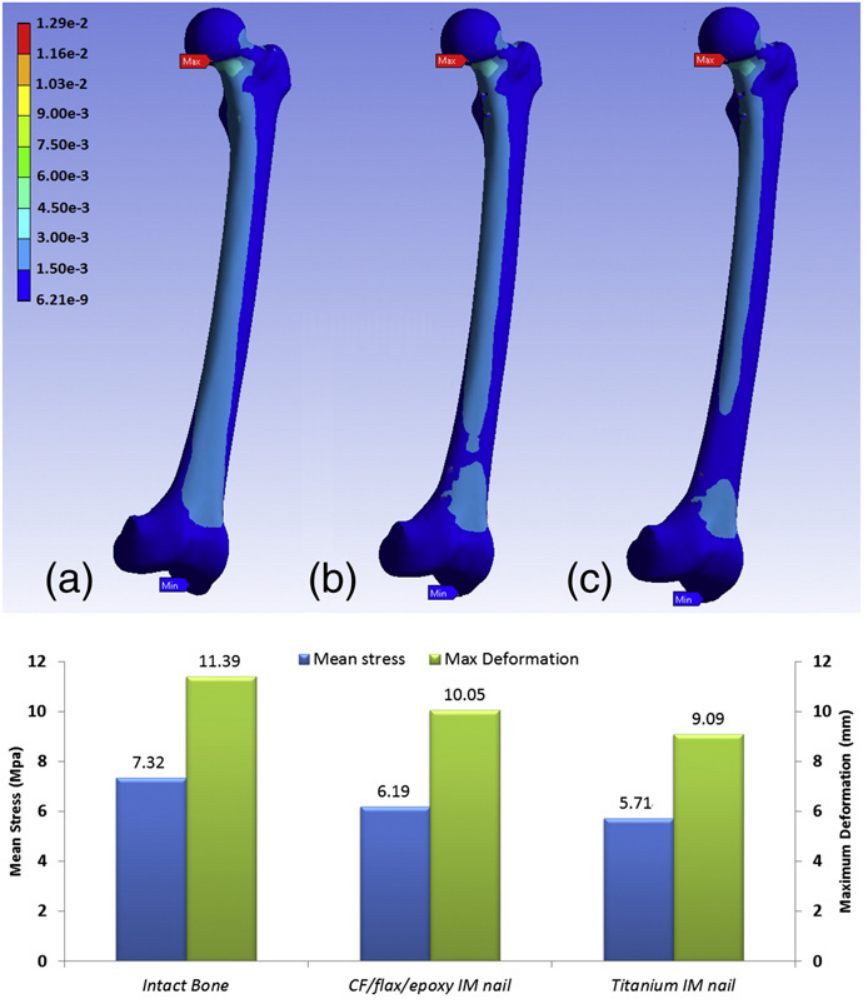

Fig. 6. Top: Strain distribution in the intact femur (a), the healed femur implanted with CF/flax/epoxy IM nail, and (c) the healed femur implanted with Ti IM nail. Bottom: Mean stress (MPa), and maximum deformation of the structure in the intact femur, the healed femur implanted with CF/flax/epoxy IM nail, and the healed femur implanted with Ti IM nail.

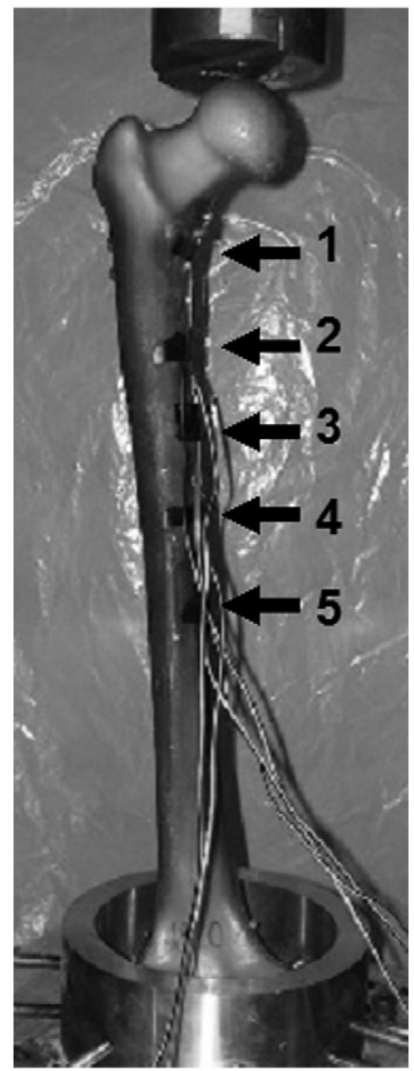

Fig. 7. Experimental setup proposed by Bougherara et al. (2009), and used to validate the current FE results. Image adapted with permission.
Table 2

Results showing axial stiffness and microstrain values at different locations of the structure at HB stage. L1-L5 refers to locations 1-5 as reported by Bougherara et al. (2009).

\begin{tabular}{lll}
\hline & Current study & Bougherara et al. (2009) \\
\hline L1 strain & 817 & 856 \\
L2 strain & 708 & 904 \\
L3 strain & 531 & 647 \\
L4 strain & 441 & 470 \\
L5 strain & 300 & 309 \\
R $^{2}$ & 0.926 & \\
Axial stiffness $(\mathrm{N} / \mathrm{mm})$ & 1378.8 & 1168.8 \\
\hline
\end{tabular}

movements which are detrimental to fracture healing (Augat et al., 2003). Therefore, controversies remain regarding the optimal fixation rigidity (Epari et al., 2007). One school of thought, referred to as selective stress shielding, suggests that the implant shields the detrimental stresses on the bone while allowing transfer of adequate amounts of beneficial stress (such as compressive stress) (Poitout, 2004). It is nearly impossible to reduce the axial stiffness of conventional Ti nails while still keeping them rigid enough in bending and torsion as the axial and bending stiffnesses are both dependant on the elastic moduli of the metal. The use of the proposed hybrid composite IM nail provides the possibility to reduce the axial stiffness with fewer reductions in the bending and torsional stiffnesses.

Among all the numerical studies that have investigated the biomechanics of IM nailing in femoral shaft fractures, very few have studied the presence of fracture (Montanini and Filardi, 2010) and still fewer considered different fracture locations and angles. This study employs a comprehensive FE model to compare the performance of a $\mathrm{CF} / \mathrm{flax} /$ epoxy and a Ti IM nail used for treating femoral shaft fractures, with consideration of the important mechanical factors in fracture healing. Two major scenarios were considered in this study: the PO stage and the HB stage.

\subsection{PO stage}

As reported in in-vivo studies, loading the fracture in the axial direction appears to boost callus formation and provide higher mechanical stiffness while decreased loading slows fracture healing (Buckwalter and Grodzinsky, 1999; Kenwright et al., 1991; Larsson et al., 2001; Terjesen and Apalset, 1988). The increase found in compressive force at the fracture site (19.9\%) as well as the stress levels in the vicinity of the fracture (28.7\%) yield an increase in the portion of loads carried by the bone and suggest that healing is improved with use of the composite IM nail. This is in agreement with previous studies that found increased loading levels on the bone with the use of less stiff materials (Cheung et al., 2004; Perez et al., 2008). However, one must bear in mind that shear movement between the fragments should be considered at the same time, as it could degrade fracture healing, even in the presence of sufficient axial loading (Augat et al., 2003). The current results showed a $36.2 \%(0.39 \mathrm{~mm})$ increase in the shear movements of the fragments with the use of a composite nail. There are controversial results regarding the effect of shear movement on fracture healing. It is assumed that shear movement at fracture sites reduces vascularization and promotes fibrous tissue differentiation (Mow and Huiskes, 2005). However, natural rapid healing has been observed in oblique fractures treated by functional bracing, where shear movement up to $4 \mathrm{~mm}$ could occur (Sarmiento et al., 1996). While some studies reported delayed healing with the presence of shear movement at fracture (Augat et al., 2003), others reported no impairments of healing (Park et al., 1998) or even improved healing with shear (Bishop et al., 2006). The effect of shear movement might be sensitive to the presence of axial motion, timing, and/or gap size (Mow and Huiskes, 2005). As depicted in Fig. $4 \mathrm{c}$, the maximum shear movement of the composite IM nail in the current study was $1.54 \mathrm{~mm}$ occurring in the distal PMDL fracture, while a $1.35 \mathrm{~mm}$ shear movement was measured in the same fracture 
fixed with Ti IM nail, showing a $0.19 \mathrm{~mm}$ increase only. The increase in the shear movement was accompanied by a simultaneous increase of compressive force at fracture site in almost all configurations. Additionally, the maximum shear movement found with the use of the new IM nail is still far below the limit reported in some experimental studies (2-4 mm) (Sarmiento et al., 1996) as being detrimental to the healing process. It was also observed that the composite nail may slightly alter the uniformity of the compressive force at the fracture site as suggested by the increase in the contact bending moment. This increase is mainly due to the increase $(0.33 \mathrm{~mm})$ of the fracture opening. As the nail is bent due to external loading, so too is the fracture opening. Therefore, the normal force at the fracture site would not be as uniform as if the nail was rigid in bending. This is more significantly observed in proximal angled fractures.

Fatigue failure of the nail and the screws, although not so common, is one of the complications of fracture fixation (Bucholz et al., 1987) and could happen in locations with high level of stress. Examining Fig. 5, one may conclude that the proximal shaft fractures result in the highest maximum stress in the implant structure compared to mid-shaft and distal fractures. This agrees well with the findings of a previous biomechanical study in which proximal and distal shaft fractures were compared (Shih et al., 2012). Proximal fractures yield shorter moment arms for the major forces acting on the head and the trochanteric region, and thus the moment acting on the fracture site would be smaller. Nevertheless, the geometry of the nail and the canal in the proximal third allows for excessive relative rotation of the bone with respect to the nail, which in turn, increases the stresses in the nail and screws. The high Young's modulus of the carbon fibers in the outer layers imparted them with a high level of tensile stress where the nail was subjected to bending stress. However, the stresses did not result in failure of the construct, according to the Tsai-Hill failure criteria in composite materials, in any configuration, owing to the high strength of carbon fibers.

Another important finding is that, regardless of the implant material, beneficial factors such as compressive normal force and mean stress around the fracture site would be lower, while the detrimental factors such as shear movement, fracture opening, and the maximum stress in the implant would mainly be higher in angled fractures. The only exception to this is the shear movement which is lower in distal PLDM as compared to distal transverse fractures. Yet, the PMDL angled fractures are deemed more critical mainly due to the state of hip joint and muscular forces on the femur which try to displace fragments and reduce stability in these fractures. The lower stability of angled fractures as compared to transverse fractures was shown in a canine study (Aro et al., 1991). The compressive normal force at fracture is also the least in PMDL angled fractures, which is inimical to healing.

Interestingly, except in PLDM cases, distal fractures showed larger shear movements and opening at fracture fragments when compared to mid-shaft or proximal shaft fractures. The condition arises from the relatively large mismatch between the canal and the nail diameter in more distal parts, which degrades the stability of the fracture. It is also sourced from the larger moment arms of the hip forces which lead to greater moments acting at the fracture site on the implant. This finding is also confirmed by prior studies that suggest inferiority of the IM nails in distal shaft fractures (Syed et al., 2004). With a PLDM fracture, the more proximal the fracture is, the more critical it would be as the shear movement and fracture opening grow.

\subsection{HB stage}

The HB stage reflects the condition in which the fracture has completely healed and the implant is expected to minimally alter the amount and the pattern of loads carried by the bone. As depicted in Fig. $6 a-c$, the strain pattern in the femur implanted with the composite IM nail was more closely aligned with those in the intact bone. Moreover, the lower deviation found in the maximum deformation of the bone implanted with the use of the composite IM nail indicates a closer structural stiffness to that of an intact bone. This, together with the higher stress levels in the bone with the proposed composite nail, can ostensibly reduce the chance of unfavorable bone resorption following healing, and is likely to reduce the risk of implant loosening or bone refracture (Lengsfeld et al., 2005; Sumner et al., 1998).

\subsection{Limitations and conclusion}

There are some limitations that should be recognized in this study. Firstly, fracture healing is a complex process that is affected by diverse factors most of which are not mechanical, and the current computational models fail to precisely simulate in-vivo phenomena. As a result, the direct application of the current results in clinical cases may not be possible prior to in-vivo tests. However, the current model overcomes several shortcomings of previous ones by considering more realistic boundary conditions and the mechanical factors involved in fracture healing. This may allow simulation of the fracture healing process and development of more efficient fracture fixation devices. Secondly, linear isotropic material properties were assumed for the bone, while nonlinearity, anisotropy, and viscoelasticity might be more characteristic of the mechanical behavior of real bones. However, previous FE comparisons of synthetic femurs with human cadaveric femurs suggest that linear material behavior is a reasonable approximation for real femurs (Cheung et al., 2004; Cristofolini et al., 1996; Papini et al., 2007).

Another limitation of the study is that only simple transverse fractures were studied, and other wedge and complex types of fractures were not considered. These might therefore be the topics of future studies.

This study considered 5 major muscles and the joint reaction force at $45 \%$ gait cycle, while other stages of gait cycle were not included. However, this should not affect the conclusion as, based on previous studies, forces and moments during stance phase are much higher than those during swing phase (Cheung et al., 2004).

Despite the mentioned limitations, the current work provides a precise numerical model to assess fracture fixation stability. Based on the findings of this study, the $\mathrm{CF} /$ flax/epoxy composite material may be an alternative to Ti as a material of choice for manufacturing IM devices. In contrast to Ti nails, load sharing in the $\mathrm{CF} / \mathrm{flax} /$ epoxy case allowed the host femur to carry most of the loads, thereby encouraging bone regrowth, and preventing bone degradation by minimizing stress shielding. In addition, using a CF/flax/epoxy IM nail in femoral shaft fractures may enhance healing by increasing the compressive normal force at fracture fragments, and by increasing the stress at the vicinity of the fracture. Biomechanically, the use of the new material has shown superior results in transverse fractures, where stability is less of a concern.

\subsection{Clinical relevance}

This work is part of ongoing research that aims to develop a hybrid composite as an alternative material for use in IM nails to reduce the negative effects of stress shielding. Several researchers have shown reduction in bone mineral density due to stress shielding around IM nails (Allen et al., 2008; Sha et al., 2009; Utvag and Reikeras, 1998). One clinical study demonstrated a statistically significant overall bone mineral density decrease in healed tibiae with retained IM nails (Allen et al., 2008). In an animal study conducted by Sha et al. (2009), a lowrigidity nail manufactured from a titanium alloy (Ti-24Nb-4Zr-7.9Sn) exhibited better external callus formation, and reduced the effects of stress shielding and bone resorption when compared to a stiffer nail. They also showed that the low-rigidity nail was sufficiently strong to maintain alignment of the fracture in the osteoporotic rat model without delayed union. The proposed flexible hybrid composite material in the present study may reduce the stress shielding effects without compromising the fracture stability. Additionally, the parameters introduced and the methodology used in the current work to evaluate the 
new material could potentially be used to improve the design of IM nails for long bone fixation.

\section{Acknowledgment}

The authors would like to thank Dr. Mansour Abolghasemian and Ms. Gillian Cook for their help in the different aspects of the study.

\section{Appendix A. Supplementary data}

Supplementary data to this article can be found online at http://dx. doi.org/10.1016/j.clinbiomech.2014.05.010.

\section{References}

Allen Jr., J.C., Lindsey, R.W., Hipp, J.A., Gugala, Z., Rianon, N., LeBlanc, A., 2008. The effect of retained intramedullary nails on tibial bone mineral density. Clin. Biomech. 23, 839-843.

Antekeier, S.B., Burden Jr., R.L., Voor, M.J., Roberts, C.S., 2005. Mechanical study of the safe distance between distal femoral fracture site and distal locking screws in antegrade intramedullary nailing. J. Orthop. Trauma 19, 693-697.

Aro, H.T., Chao, E.Y., 1993. Bone-healing patterns affected by loading, fracture fragment stability, fracture type, and fracture site compression. Clin. Orthop. Relat. Res. 8-17.

Aro, H.T. Wahner, H.T., Chao, E.Y., 1991. Healing patterns of transverse and oblique osteotomies in the canine tibia under external fixation. J. Orthop. Trauma 5, 351-364.

Augat, P., Burger, J., Schorlemmer, S., Henke, T., Peraus, M., Claes, L., 2003. Shear movement at the fracture site delays healing in a diaphyseal fracture model. J. Orthop. Res. 21, 1011-1017.

Bagheri, Z.S., El Sawi, I., Schemitsch, E.H., Zdero, R., Bougherara, H., 2013. Biomechanical properties of an advanced new carbon/flax/epoxy composite material for bone plate applications. J. Mech. Behav. Biomed. Mater. 20, 398-406.

Bishop, N.E., Van Rhijn, M., Tami, I., Corveleijn, R., Schneider, E., Ito, K., 2006. Shear does not necessarily inhibit bone healing. Clin. Orthop. Relat. Res. 307-314.

Bitsakos, C., Kerner, J., Fisher, I., Amis, A.A., 2005. The effect of muscle loading on the simulation of bone remodelling in the proximal femur. J. Biomech. 38, 133-139.

Bougherara, H., Zdero, R., Miric, M., Shah, S., Hardisty, M., Zalzal, P., et al., 2009. The biomechanics of the T2 femoral nailing system: a comparison of synthetic femurs with finite element analysis. Proc. Inst. Mech. Eng. H 223, 303-314.

Braten, M., Terjesen, T., Rossvoll, I., 1995. Femoral shaft fractures treated by intramedullary nailing. A follow-up study focusing on problems related to the method. Injury 26 , 379-383.

Browner, B.D., 2009. Skeletal Trauma: Basic Science, Management, and Reconstruction. Saunders/Elsevier.

Bucholz, R.W., Ross, S.E., Lawrence, K.L., 1987. Fatigue fracture of the interlocking nail in the treatment of fractures of the distal part of the femoral shaft. J. Bone Joint Surg. Am. 69, 1391-1399.

Buckwalter, J.A., Grodzinsky, A.J., 1999. Loading of healing bone, fibrous tissue, and muscle: implications for orthopaedic practice. J. Am. Acad. Orthop. Surg. 7, 291-299.

Charlet, K., Jernot, J.P., Gomina, M., Bizet, L., 2010. Mechanical properties of flax fibers and of the derived unidirectional composites. J. Compos. Mater. 44, 2887-2896.

Cheung, G., Zalzal, P., Bhandari, M., Spelt, J.K., Papini, M., 2004. Finite element analysis of a femoral retrograde intramedullary nail subject to gait loading. Med. Eng. Phys. 26, 93-108.

Cifuentes, S.C., Frutos, E., González-Carrasco, J.L., Muñoz, M., Multigner, M., Chao, J., et al., 2012. Novel PLLA/magnesium composite for orthopedic applications: a proof of concept. Mater. Lett. 74, 239-242.

Cristofolini, L., Viceconti, M., Cappello, A., Toni, A., 1996. Mechanical validation of whole bone composite femur models. J. Biomech. 29, 525-535.

Duda, G.N., Schneider, E., Chao, E.Y., 1997. Internal forces and moments in the femur during walking. J. Biomech. 30, 933-941.

Duda, G.N., Heller, M., Albinger, J., Schulz, O., Schneider, E., Claes, L., 1998. Influence of muscle forces on femoral strain distribution. J. Biomech. 31, 841-846.

Epari, D.R., Kassi, J.P., Schell, H., Duda, G.N., 2007. Timely fracture-healing requires optimization of axial fixation stability. J. Bone Joint Surg. Am. 89, 1575-1585.
Eveleigh, R.J., 1995. A review of biomechanical studies of intramedullary nails. Med. Eng. Phys. 17, 323-331.

Gardner, M.P., Chong, A.C.M., Pollock, A.G., Wooley, P.H., 2010. Mechanical evaluation of large-size fourth-generation composite femur and tibia models. Ann. Biomed. Eng. $38,613-620$.

Grassi, L., Väänänen, S.P., Amin, Yavari S., Weinans, H., Jurvelin, J.S., Zadpoor, A.A., et al., 2013. Experimental validation of finite element model for proximal composite femur using optical measurements. J. Mech. Behav. Biomed. Mater. 21, 86-94.

Heiner, A.D., 2008. Structural properties of fourth-generation composite femurs and tibias. J. Biomech. 41, 3282-3284.

Kenwright, J., Goodship, A.E., 1989. Controlled mechanical stimulation in the treatment of tibial fractures. Clin. Orthop. Relat. Res. 36-47.

Kenwright, J., Richardson, J.B., Cunningham, J.L., White, S.H., Goodship, A.E., Adams, M.A. et al., 1991. Axial movement and tibial fractures. A controlled randomised trial of treatment. J. Bone Joint Surg. (Br.) 73, 654-659.

Larsson, S., Kim, W., Caja, V.L., Egger, E.L., Inoue, N., Chao, E.Y., 2001. Effect of early axia dynamization on tibial bone healing: a study in dogs. Clin. Orthop. Relat. Res. 240-251.

Lengsfeld, M., Burchard, R., Gunther, D., Pressel, T., Schmitt, J., Leppek, R., et al., 2005. Femoral strain changes after total hip arthroplasty - patient-specific finite element analyses 12 years after operation. Med. Eng. Phys. 27, 649-654.

Mantripragada, V.P., Lecka-Czernik, B., Ebraheim, N.A., Jayasuriya, A.C., 2013. An overview of recent advances in designing orthopedic and craniofacial implants. J. Biomed. Mater. Res. A 101, 3349-3364.

Montanini, R., Filardi, V., 2010. In vitro biomechanical evaluation of antegrade femoral nailing at early and late postoperative stages. Med. Eng. Phys. 32, 889-897.

Mow, V.C., Huiskes, R., 2005. Basic Orthopaedic Biomechanics \& Mechano-biology Lippincott Williams \& Wilkins.

Papini, M., Zdero, R. Schemitsch, E.H., Zalzal, P. 2007. The biomechanics of human femurs in axial and torsional loading: comparison of finite element analysis, human cadaveric femurs, and synthetic femurs. J. Biomech. Eng. 129, 12-19.

Park, S.H., O'Connor, K., McKellop, H., Sarmiento, A., 1998. The influence of active shear or compressive motion on fracture-healing. J. Bone Joint Surg. Am. 80, 868-878.

Perez, A., Mahar, A., Negus, C., Newton, P., Impelluso, T., 2008. A computational evaluation of the effect of intramedullary nail material properties on the stabilization of simulated femoral shaft fractures. Med. Eng. Phys. 30, 755-760.

Poitout, D.G., 2004. Biomechanics and Biomaterials in Orthopedics. Springer.

Sarmiento, A., McKellop, H.A., Llinas, A., Park, S.H., Lu, B., Stetson, W., et al., 1996. Effect of loading and fracture motions on diaphyseal tibial fractures. J. Orthop. Res. 14, 80-84

Sha, M., Guo, Z., Fu, J., Li, J., Yuan, C.F., Shi, L., et al., 2009. The effects of nail rigidity on fracture healing in rats with osteoporosis. Acta Orthop. 80, 135-138.

Shih, K.S., Hsu, C.C., Hsu, T.P., 2012. A biomechanical investigation of the effects of static fixation and dynamization after interlocking femoral nailing: a finite element study. J. Trauma Acute Care Surg. 72, E46-E53.

Suchý, T., Balík, K., Sedláček, R., Sucharda, Z., Sochor, M., Prokop, J., et al., 2011. Radiolucent composites providing high resistance against sterilization decomposition. Ceram. Silik. 55, 401-409.

Sumner, D.R., Turner, T.M., Igloria, R., Urban, R.M., Galante, J.O., 1998. Functional adaptation and ingrowth of bone vary as a function of hip implant stiffness. J. Biomech. 31, 909-917.

Syed, A.A., Agarwal, M., Giannoudis, P.V., Matthews, S.J., Smith, R.M., 2004. Distal femoral fractures: long-term outcome following stabilisation with the LISS. Injury 35 599-607.

Tavakkoli Avval, P., Klika, V., Bougherara, H., 2014. Predicting bone remodeling in response to total hip arthroplasty: computational study using mechanobiochemical model. J. Biomech. Eng. 136, 051002.

Terjesen, T., Apalset, K., 1988. The influence of different degrees of stiffness of fixation plates on experimental bone healing. J. Orthop. Res. 6, 293-299.

Utvag, S.E., Reikeras, O., 1998. Effects of nail rigidity on fracture healing. Strength and mineralisation in rat femoral bone. Arch. Orthop. Trauma Surg. 118, 7-13.

Viceconti, M., Bellingeri, L., Cristofolini, L., Toni, A., 1998. A comparative study on different methods of automatic mesh generation of human femurs. Med. Eng. Phys. 20, 1-10.

Viceconti, M., Olsen, S., Nolte, L.P., Burton, K., 2005. Extracting clinically relevant data from finite element simulations. Clin. Biomech. 20, 451-454.

Wolff, J., Maquet, P., Furlong, R., 1986. The Law of Bone Remodelling. Springer-Verlag.

Zdero, R., Bougherara, H., Dubov, A., Shah, S., Zalzal, P., Mahfud, A., et al., 2010. The effect of cortex thickness on intact femur biomechanics: a comparison of finite element analysis with synthetic femurs. Proceedings of the Institution of Mechanical Engineers. J. Eng. Med. H 224, 831-840. 